\title{
CLASSIFICATION, CHARACTERIZATION AND ABSTRACTION OF VEGETABLE SURFACES FOR DESIGN
}

\author{
EVER PATIÑO, DAVID A. TORREBLANCA-DÍAZ, ANDRÉS VALENCIA-ESCOBAR \& \\ ALEJANDRO ZULETA \\ Facultad de Diseño Industrial, Universidad Pontificia Bolivariana, Colombia.
}

\begin{abstract}
Biological design tools such as biomimicry and bio-inspiration are increasingly used resources to solve design and engineering problems, owing to their high probability of finding efficient technical solutions and novel morphologies with the potential to positively impact the environment. This article focuses on the development of a methodology for the morphological characterization of plant surfaces, which can be applied in a conventional design or research project based on biological information. The process proposed here is part of the results of the research project 'Repertory of bio-inspired surfaces and textures, through morphological experiments with Digital Manufacturing Technologies'. For the development of the characterization, the observation and selection of 225 species, which were grouped and categorized based on the predominant geometric characteristics, resulting in six categories: basic geometries, reciprocals, reliefs, ramifications, folds and visual texture. Then, the natural models were evaluated qualitatively and the representative samples of each category to later perform the process of digital abstraction using CAD and parametric tools. In the process of abstraction a description and visual analysis is made from: transition points, contours, symmetries, cross-sections and basic patterns as straight lines, sections of circle, circumferences, ellipses and/or parabolas. It was possible to verify that the three-dimensional interpretation that was made digitally of the textures, preserve the fundamental morphological properties, in addition to, to keep a direct relationship with the category to which they belong, achieving a balance between the faithful copy and the abstract copy; this in order to maintain the formal properties with potential to be applied in future design projects.
\end{abstract}

Keywords: abstraction, analogy, biomimicry, bio-inspiration, design, plant surfaces, textures.

\section{INTRODUCTION}

Bio-inspiration is part of the so-called biologically informed design disciplines, to which biomimetics and bionics also belong [1]. This large umbrella shelters the disciplines that take as reference to nature for the solution of human problems. This reference can focus on the identification, analysis and synthesis of principles or laws of operation, materialization or formal configuration of natural origin, which in some way provide support to the project. Similarly, it has been proved that if an industrial object is designed based on a biologically informed design, it will be more likely to acquire a series of characteristics that will make it innovative and efficient [2-4].

Also, the development of functional surfaces obtained from the copy of textures present in nature has aroused much interest owing to the various applications that can be derived from this exercise. An example of this is the work developed by Tsipenyuk and Varenberg [5], who analyzed the effect of hexagonal textures present on the skin of amphibians on the coefficient of friction, this in order to use said texture in the optimization of the design of shaving machines. It was found that the designed biomimetic surface improves the performance of the product by approximately twice. Similar exercises have been carried out by researchers [6-9], who have focused their research on the development of superhydrophobic surfaces [9], oleophobic [10] and wear resistant [11], from the textures present in the plants. Lee et al. [12] replicated the surface micro and nanotextures of plant leaves in an ultraviolet (UV) curable polymer. The sheet was joined and pressed against a UV curable polymer in order to transfer 
the patterns of the sheet to the polymer. It was found that the technique employed generated polymeric surfaces with remarkable increase in the hydrophobicity of the replicated films in contrast to the unmodified substrates.

Despite the above, there is little information that counts for a systematic study that addresses in detail the exercise of abstraction of diversity of texture patterns present in nature, specifically in plants, so that these can be applied in biologically informed design exercises; in particular, in bio-inspiration processes, where the analogy of the biological systems is used, to apply its characteristic by means of the association of a design or engineering problem [13]. In other words, design by analogy seeks to study a specific domain in order to transfer information to another domain that presents any problems [14].

The Biomimicry Institute proposes the methodology called 'Challenge to Biology Design Spiral', which comprises five phases that the designer should approach in an iterative and cyclical process: (i) Distill the design function, (ii) Translate to biology, (iii) Discover natural models, (iv) Emulate nature's strategies and (v) Evaluate the design. In phase (vi) the form is imitated but it is not explicit how to translate the natural models into forms and structures applicable to the design project. Although there is an imitation, it should take different depths and levels depending on the design project.

Likewise, Helms et al. [13] proposed an interactive feedback process comprised of six stages: (i) problem definition, (ii) problem reframing, (iii) biological solution search, (iv) biological solution definition, $(v)$ principle extraction and (vi) principle application. In the last step, the designers translate the principle extracted from the biological domain into a new domain of design, which is the one posed from the new requirements entry level and the use of composite analogies; but again, they do not specify the procedure to achieve it.

Otherwise, Volstad and Boks [15] reviewed three data bases of natural analogies and proposed 'The Biomimicry Card Deck', which is a biomimicry tool put in service to look for solutions in nature. However, these tools enunciate possible solutions but they do not explain how to use them. Similarly, Appio et al. [16] reviewed seven biomimicry tools frequently used by designers who know about the subject. The tools are focused on finding the biological principle or analogy, extracting it and generating concepts even though they do not describe in detail the process of abstracting and applying the analogy.

That is why, in order to design a repertoire of bio-inspired surfaces and textures for professionals in the cultural and creative industries, the project 'Repertory of bio-inspired surfaces and textures, through morphological experimentation with digital fabrication technologies' originates, which seeks to develop a catalog in open source, customizable and online where designers, architects or other creative professionals can extract the best solution for a specific problem in the field of surfaces and textures of objects, textiles and/or spaces.

In the context of this particular project, and in relation to design by analogy, the first domain refers to the geometric characteristics of the plant surface, and the second domain to the textures of objects, textiles and spaces.

The surface (first domain) has been of great interest for the development of design projects, considering that the surface is the border separating the interior from the exterior of an organism [17], it is this portion of the organism or object that will interact directly with the external agents and the one that must respond to specific needs that differ according to the function that this needs to supply, because it can delimit giving shape to the individual and providing structure to the body; it can be a barrier against dry, humid, cold and/or hot environments; in some cases, it is part of the breathing and it transports gases and secretions; they are part of thermoregulation by the use of pigments and chemical components and often intervene in 
communication systems; and many of the specialized surfaces are part of mechanisms, retain air, grind food and cleanse the body [18]. In all cases, they are complex forms that have to respond to multiple and diverse requirements of the environment.

On the other hand, based on a biological reference within the design process, it is common to leave the task to the designer to visually abstract the natural model without objectively setting limits or conditions. This is a cognitive process that is part of the analogical reasoning where the designer transfers the founded information in the domain of origin into the domain of application or destination from forms and geometries [16]. This leads to several disadvantages, including different cognitive factors that can vary from researcher to researcher, such as memory, expertise and the frequency to which he has been exposed to the analogy [19]. The response that one has of the stimulus would then determine to a large extent the result of the abstraction.

The main purpose of this article is to propose a design methodology to perform the characterization of natural models, specifically the surface textures of these, then, from the analysis and synthesis, to make abstraction of texture models that can be used for the development of biomimetic or bio-inspired design or research projects.

\section{METHODOLOGY}

From a qualitative approach a descriptive methodology based on four phases was approached: (i) preliminary observation, (ii) classification of patterns, (iii) selection of natural models and (iv) geometric abstraction (see Fig. 1).

For the preliminary observation phase, the study objects were delimited through the selection of specimens present in the plant kingdom and in the mushroom kingdom of the city of Medellín, Colombia. These two kingdoms were selected because of the possibility of finding specimens in abundance in the near environment and because of the feasibility of collection of samples. To compile the information from this phase, an observation instrument was designed in accordance with four main requirements: basic information, plant classification, geometric classification, photographic record and recommendations. In the basic information and taking into account that it is a preliminary observation that allows in the medium term to collect samples, the following information is recorded: photographer, date, place of the photograph, common name, scientific name and name of the files originals. The vegetal classification was determined by the type of surface and its objective was to divide the search in the field; this did not respond to a biological categorization, but to the possibility of finding different natural models depending on the natural morphology: leaves, barks and stems, flowers, fruits and seeds, and finally mosses, lichens and fungi.

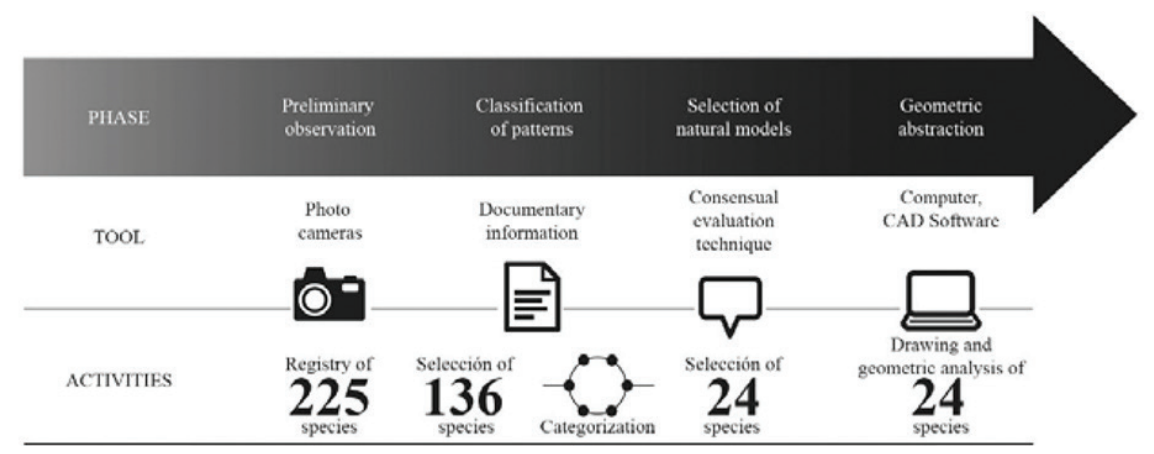

Figure 1: Schematic diagram of the methodology. 
The photographs were captured using three cameras with the following characteristics: Canon 7D with 17-40 mm lens, Canon Eos Rebel T5 with $100 \mathrm{~mm}$ macro lens and Canon $60 \mathrm{D}$ with $18-55 \mathrm{~mm}$ lens. Likewise, the record was always made perpendicular to the surface; a ruler was placed in one of the photographs to size the natural model and the samples were placed in white backgrounds with natural light input so as not to change the colors and allow an adequate contrast between the lights and the shadows of the photographs. In addition, from the point of view of photographic quality, the same parameters of composition, focus and resolution were taken into account in order to obtain comparable photographs among them in such a way that they could be analyzed in a similar way.

In the first observation phase, 225 plant species of the 2.603 registered in Medellin (Alcaldía de Medellín, 2014) were photographically documented, which represents the $8 \%$ of the urban plants in the city. Therefore, it was necessary in the pattern classification phase to carry out an ordered and systematic debugging of the information based on the photographic quality. Photos that did not meet the criteria of good lighting, adequate focus, sufficient contrast to visualize the textures and above all that did not present relevant visual information were discarded. In total, 136 natural models remained.

The classification phase of the patterns was carried out based on the crossing of documentary information and its interrelation with the predominant characteristics registered in the first instrument. After making the classification natural models were selected to be abstracted. For this, a test was designed with a group of experts in morphology and biomimetics where a consensual evaluation technique was used.

Finally, in the abstraction phase a two-dimensional and three-dimensional geometric analyses were made using the Rhinoceros ${ }^{\circledR}$ CAD software, this information was placed into a graphic registration instrument. In this phase, 24 abstractions of different natural models were developed.

\section{RESULTS AND DISCUSSION}

The 136 selected natural models were grouped after determining their predominant morphological characteristics, for which, the information collected in the geometric classification, basically Euclidean, of the observation instrument was used and compared with the classifications of formal patterns in nature proposed by different authors such as Wagensberg [17], Stevens [20], Otto [21], Aranda and Lasch [22], Arbeláez and Patiño [23] and ValenciaEscobar [24] and Escobar [25]. These classifications respond in their majority to predominant geometric patterns in all the kingdoms of the nature, in all types of structures and for all types of functions. Otto is the only one who approached natural surfaces but seen from all the complexity of construction in the universe. In this specific case, as the object of study was the textures present in the plant surfaces, the preponderance of one and the other pattern changed considerably. This led to the generation of a new classification, which is nothing more than a new ordering of the categories proposed by the authors mentioned above.

There were 12 groups that were grouped and ranked until reaching only six categories with their respective subcategories. The categories respond to a grouping according to the most relevant morphological characteristics, such as: basic geometries, reciprocals, reliefs, ramifications, folds and visual texture. They are also not exclusive, if not on the contrary, it is possible that a texture is located in a category but thanks to the multifunctionality of the biological surfaces, it can include properties that respond with less visual relevance to another category. In the classification, the preponderance of some formal characteristics was observed over others present in the plant biological surfaces, but since the objective of the project was 
not to verify the frequency of the different patterns, all were grouped and classified equally, regardless of the amount of collected models. The following sections provide a summary of each of the categories.

\subsection{Basic geometries}

They are based on the basic designs proposed by Stevens [20] in the book Patterns and Patterns in Nature, which, in turn, pick up elements from the book 'On Growth and Form' by Thompson [26]. In general aspects, this refers to the morphologies of textures that can be described from the basic concepts of Euclidean geometry, such as lines, angles, the consecutive formation of polygons and their relationship with symmetries.

The morphologies that can be perfect in the mathematical descriptions of Euclid are not necessarily present in nature because of the presence of imperfections, fluctuations, protuberances and/or depressions [27]. Although curved geometries predominate in nature [17], some straight geometries are also present, mostly with the aim of minimizing lengths and materials [23].

The basic geometries are divided into four subcategories: the lines, the diamonds, the circles and the Voronoi diagrams. In Fig. 2, there is an example of the classification made.

\subsection{Reciprocal geometries}

A reciprocal structure is formed by modules that support each other forming a closed system where there is no structural hierarchy, that is to say, there is no module more important than the other one $[28,29]$. Structures of modules that are repeated can be found in this category, sharing the direction and mechanism of opening of the vegetable; this makes the drive of all modules to be interconnected such that a change of pressure in one of the modules promotes the whole system to self-balance from the self-organization and the joint work of the parts [30].

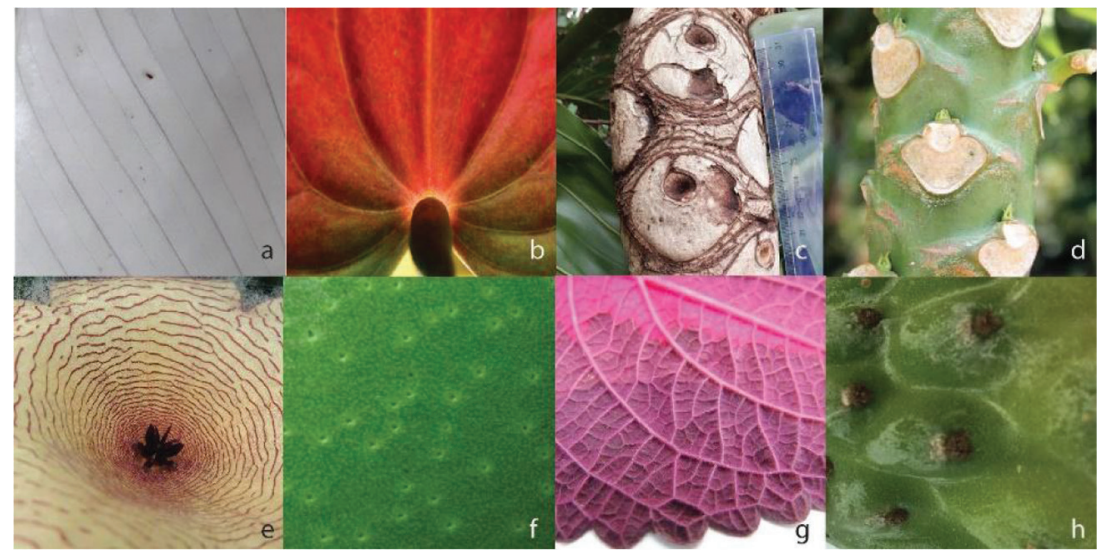

Figure 2: Basic geometries: (a) straight line, (b) curved line in explosion, (c) and (d) diamonds, (e) circular concentric, (f) modular circular, (g) flat Voronoi and (h) Voronoi stellate (Photos: Morfolab, Universidad Pontificia Bolivariana). 


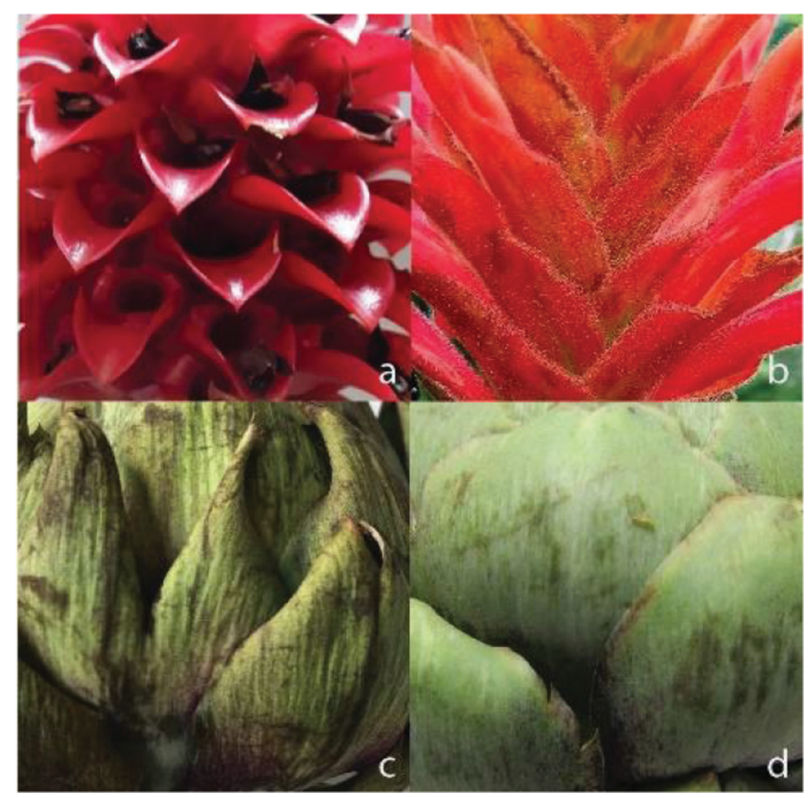

Figure 3: Reciprocal geometries: (a) and (b) open, (c) and (d) closed (Photos: Morfolab, Universidad Pontificia Bolivariana).

On the other hand, it can be seen most of the time that the modules are supported on each other and that where one module ends another one begins and so on until the structural system closes. This category is further divided into two subcategories: open and closed (Fig. 3).

This grouping is related to the degree of maturation and is in direct proportion to the moisture of the model found. The modules of the system open by an increase in turgor pressure in the cells and closed by a decrease in turgor pressure [31]. That is, in this specific case, more than in the other categories, division is a temporary matter and has a more practical meaning since the same natural model, depending on its age, or turgor pressures is either open or closed.

\subsection{Reliefs}

In all categories, with the exception of the visual texture, the geometries protrude in some way to the three-dimensionality, but in this category are the natural models are projected from the base surface as beaks and peaks. In the plants, the reliefs are multifunctional since they maintain the physiological integrity and limit the loss of water, avoiding desiccation as well as providing protection against radiation, mechanical resistance and in some cases selfcleaning properties [32]. Additionally, spines and tips can be provided to protect them against harmful external agents [17].

Unlike the category of folds, the relief does not move along the entire surface, but even if it is repeated, one could explain how a network of multiple points in space pulls the material generally perpendicular to the center. Relief is divided into three subcategories: linear, synclastic and conoid (Fig. 4). 


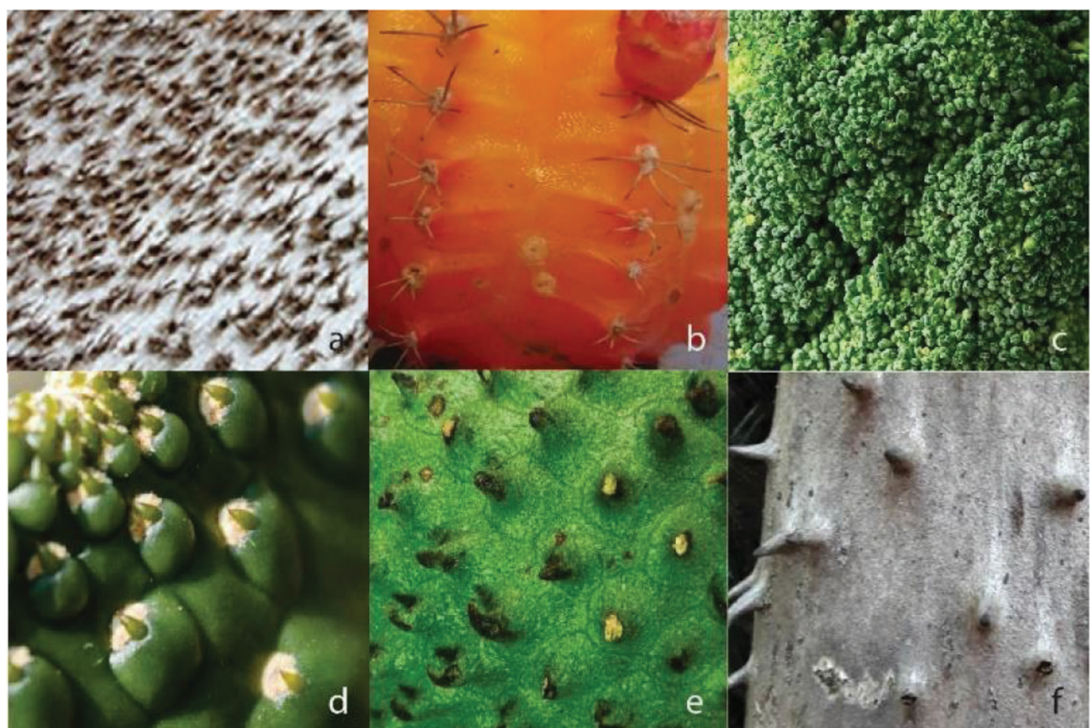

Figure 4: Relief: (a) modular linear, (b) linear in explosion, (c) and (d) synclastics, (e) and (f) conoides (Photos: Morfolab, Universidad Pontificia Bolivariana).

\subsection{Branches}

Branches are one of the most common forms of growth in nature and are present in plants, fluvial networks, lungs and snowflakes [33]. Branches are present in plants in different means and sizes in order to maximize the occupied area, and thus increasing the uptake of energy during the process of photosynthesis. To reach the largest possible surface, the plant must make use of the ramifications; the more different the morphology of the plant from the morphology of the sphere is, the greater its growth, since the surface of a sphere is small in relation to its volume [34].

Stevens [20] mentions that if a system must be evenly distributed through space, it must be opened in a fan-like fashion looking for the periphery, whether it is a bi- or three-dimensional space. The most optimal strategy to do so is to create bifurcations that manifest themselves as they move away from the center in a greater number of smaller trajectories. As can be seen in Fig. 5, this category is divided into basic branches and fractals. Basic branches are in their entirety ribbed leaves and fractals are three-dimensional compositions of a lichen. In many of the samples found, Voronoi diagrams are also less relevant and smaller; there is also a presence of fractal structures but the frequency, or change of scale, is not as periodic as the lichen of the second category. That is, there is fractality but incipient, with a very rare change of scale that does not allow the fractality to develop in its entirety.

\subsection{Folds}

This category is present in the plants to increase the structural capacity without adding or changing the material. This is achieved by moving the greater amount of material away from the center of mass of the surface by means of folds and double-curved shells. For example, the leaf of the 


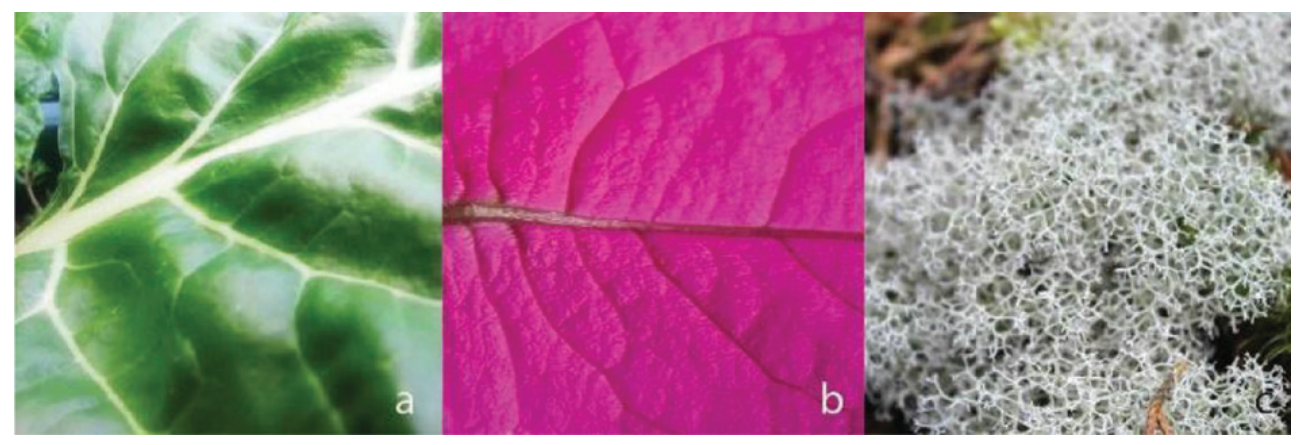

Figure 5: Branches: (a) and (b) basic and (c) fractals (Photos: Morfolab, Universidad Pontificia Bolivariana).

Pritchardia pacifica, shown in Fig. 5c, increases its structural strength a thousand times in contrast with a smooth leaf [35]. In this category are the natural models that, like the reliefs, have a projection of their surface, but in this case they are not points that are projected above the surface, but are regular and irregular continuous lines that pull the material geometrically. This category is further subdivided into sinuous folds, regular straight folds and irregular folds (Fig. 6).

\subsection{Visual texture}

Another function of the surfaces in plants is to provide signals for the recognition of pathogens, insects and the development of epidermal cells [36]. This category includes natural models that, from a macro view, do not show three-dimensional changes in texture. That is to say, as natural geometries they have in themselves a certain volume, but in the texture of their surface they present changes of color that generate visual changes in their geometric composition. In Fig. 7, different models can be found, grouped in the following sub-categories: regular pattern as circles and lines with symmetries, and irregular pattern. In both cases there are changes that obey more to a variation in pigmentation of the specimen, than to geometric and structural property.

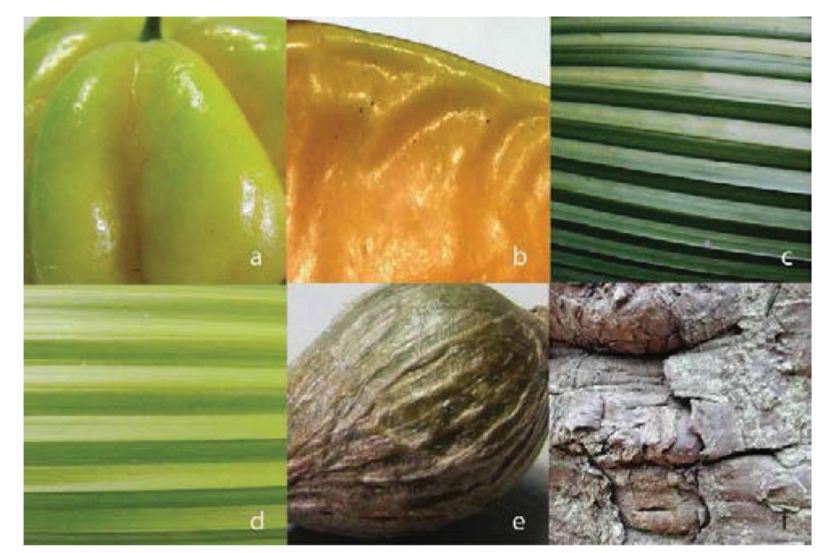

Figure 6: Folds: (a) and (b) winding, (c) and (d) regular straight, (e) and (f) irregular (Photos: Morfolab, Universidad Pontificia Bolivariana). 


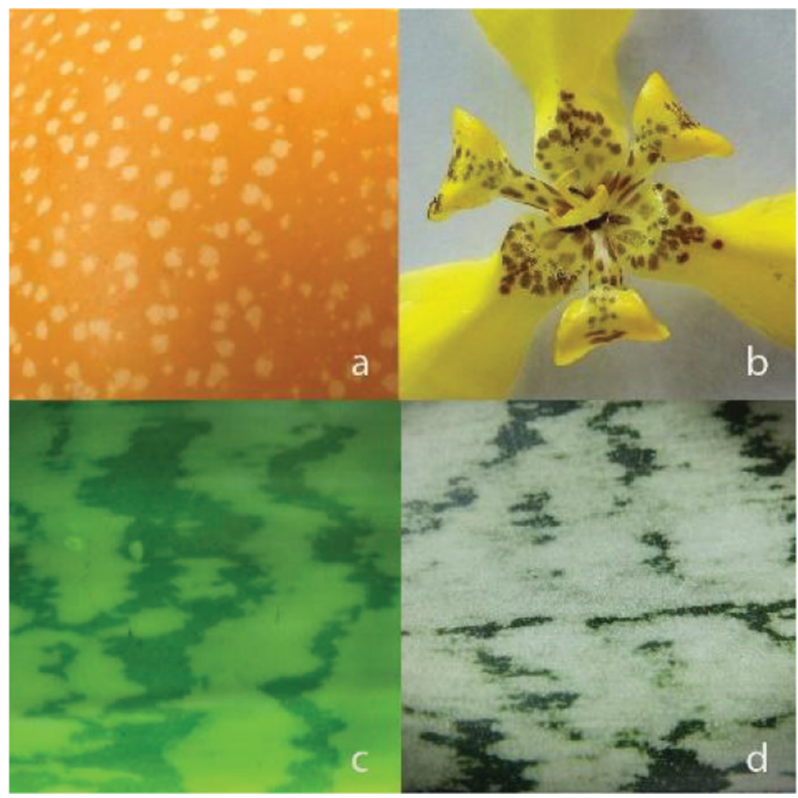

Figure 7: Visual texture: (a) and (b) regular pattern, (c) and (d) irregular pattern (Photos: Morfolab, Universidad Pontificia Bolivariana).

On the other hand, in the third phase, three classification criteria were determined, which allowed, according to the highest rating, to select the ideal natural model by category to make the subsequent abstraction. In the evaluation, a group of professionals specialized in morphology, geometry, materials and design participated, and a Likert scale of five items was used: nothing, little, neutral, enough and a lot [37]. The criteria are described as below:

- Frequency: Defined by Wagensberg [17] as one of the external properties of shapes and objects, frequency is simply the number of individuals who share similar morphological properties. It is also related to the diversity of forms, that is, the variations present in models that share properties. In order to select less explored models, for this case, the less frequent, the higher their valuation.

- Perspective of utility: Baumeister [38] determines the possibility of building bridges between natural models and their possible applications as one of the essential elements of biomimicry, these are given by the recognition of the opportunity to use ideas of nature to obtain some physical and/or material benefit.

- Visual attraction: Likewise, Baumeister [38] mentions another equally relevant element, the esthetic connection, defined as the relationship that allows the observer to feel attracted to a natural model. Baumeister says that it is very difficult to find a person who maintains that nature is 'ugly', since such attraction and elegance seems to be far above naturalistic philosophical thoughts, which place nature as a primitive humanitarian principle, and therefore, beautiful by itself.

Thus the previous process gave a result of 24 selected species: A. Comosus Variegatus, Anthurium andraeanum, Musa coccinea, Microsorum musifolium, Phoenix canariensis, Stapelia grandiflora, Fragaria ananassa, Cucumis melo, Artocarpus heterophyllus, Costus 
costaceae, Pinus pinea, Nephelium lappaceum, Bismarchia nobilis, Spathiphyllum Walliss, Justicia brandegeana, Icmadophila adversa, Eugenia uniflora, Washingtonia robusta, Blighia sapida, Sansevieria trifasciata and four varieties of Cucurbita pepo convar. Microcarpine.

After the selection, the last phase of the process was continued, referring to the abstraction of the forms found. For this, it was necessary to first define the level of abstraction required for the project and methodologically determine the steps to carry out this activity in the most objective way possible. Historically, this is a phase in which methodologically it has not been deepened and, paradoxically, it is here that many of the final qualities that the finished product will have are defined. According to Comanns et al. [39], in this stage it is necessary to arrive at sufficient abstraction, where the coincidence and the adjustment between the natural model and the artificial texture is direct, achieving that the developed visual description allows for the identification of the characteristics that make the texture unique and relevant.

Knowing that abstraction is an inductive process in which conclusions are drawn, in this case visual, based on the observation of biological models [40], an instrument was designed to systematically visualize the most economically possible interpretation based on the law of Prägnanz and in general of the principles of perceptual organization of the Gestalt [41] since it has already been verified that the geometric follow-up of these principles leads to the generation of patterns that are preferred over others that do not use them $[42,43]$. The instrument to achieve this objective is divided into three parts, the first is the preliminary stage where the results of the observation are integrated; the second, is the stage of geometric study, where two-dimensional information is plotted using Rhinoceros CAD software and is based on transition points, contours, symmetries, cross-sections and basic patterns such as straight lines, circle sections, circumferences, ellipses and/or parabolas. And the third stage is that of digital modeling, where, also with the Rhinoceros software, the result of the abstraction is modeled three-dimensionally and a repetition of the module is made on a flat surface. The purpose of this last repetition is to validate the usefulness of the module and to check whether the visual excitation potential of the texture generates a pleasant perception, achieving a balance between the complex and the varied [41]. Figures 8-14 show some of the abstraction processes developed in the project.

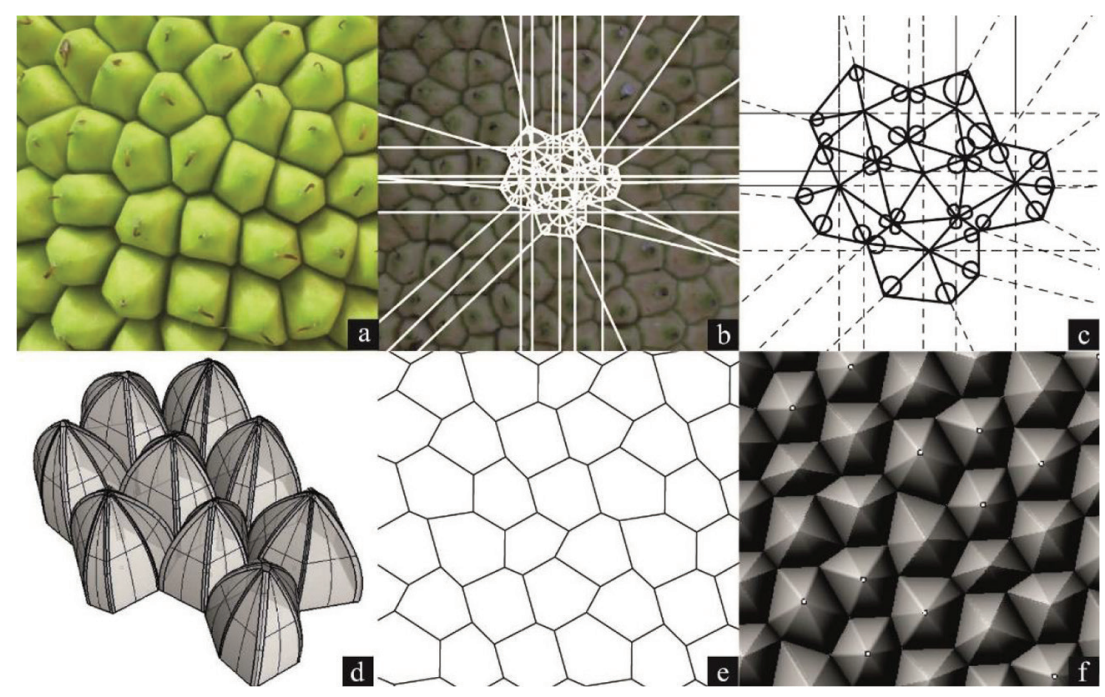

Figure 8: Process of characterization and abstraction of the fruit of Artocarpus heterophyllus. Basic geometries category. (Photography and digital modeling of Julio Zuluaga). 


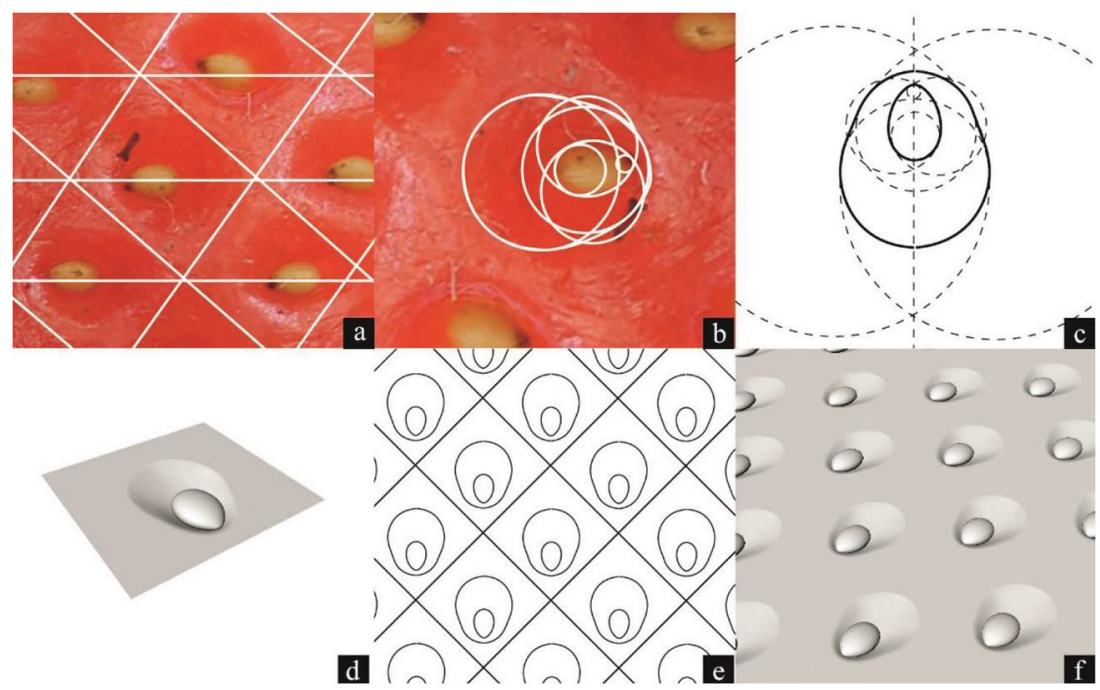

Figure 9: Process of characterization and abstraction of the Ananassa fragaria. Basic geometries category. (Photography and digital modeling of Laura Vargas).

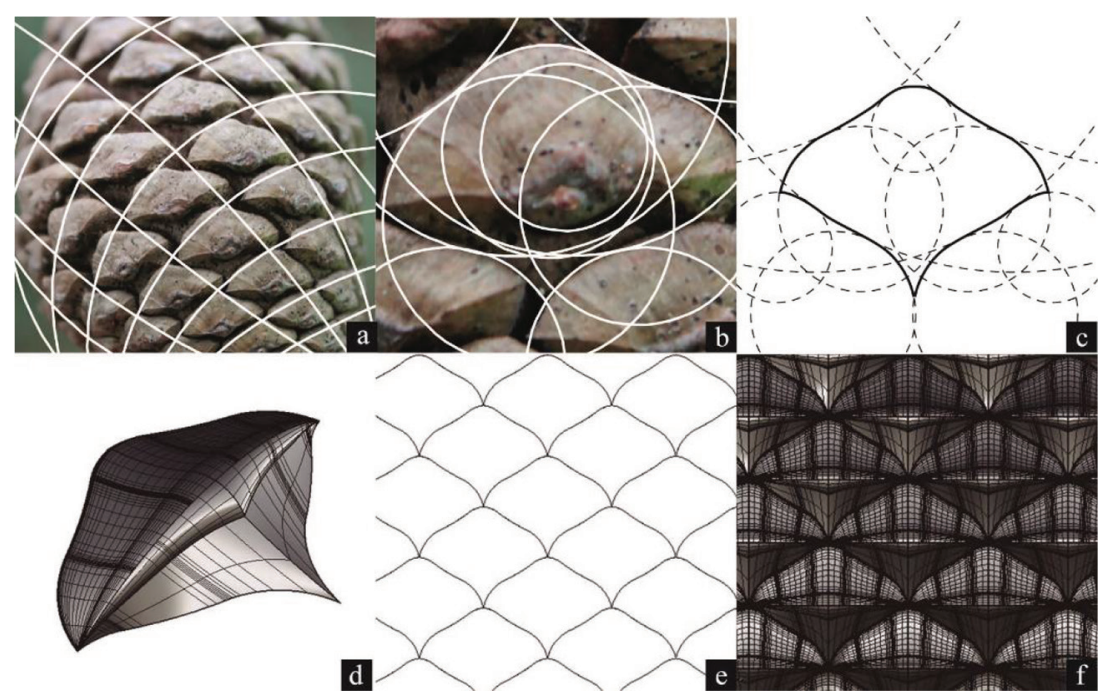

Figure 10: Process of characterization and abstraction of the Pinus pinea seed. Reciprocal geometries category (Photography by Pablo Montes and digital modeling by Julian Villa). 

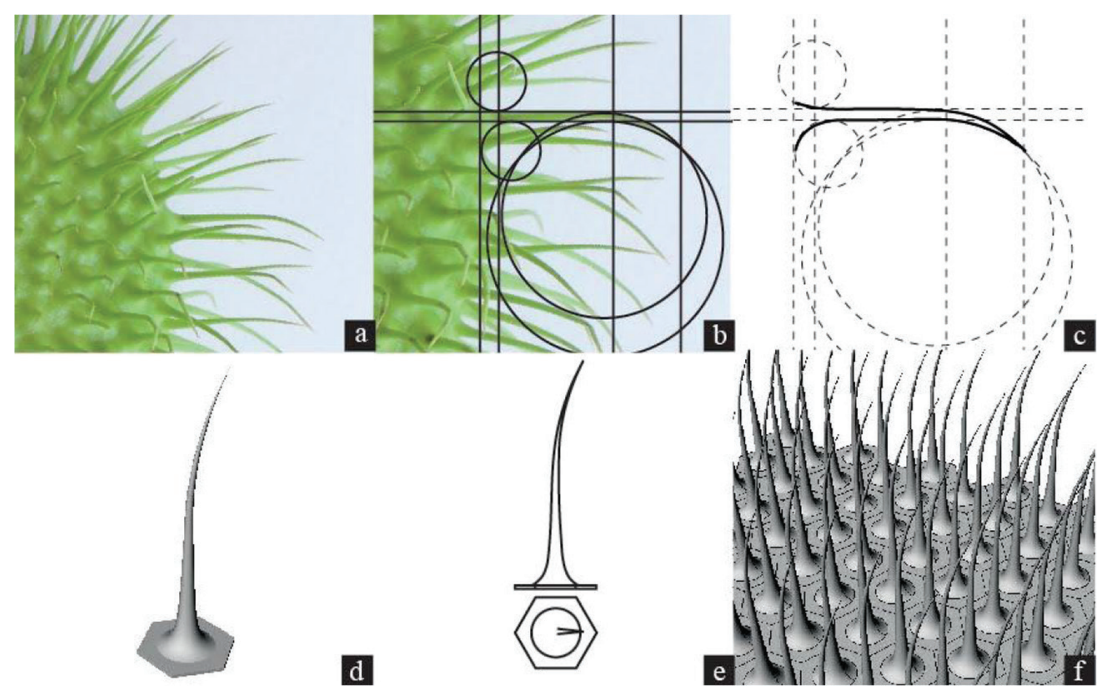

Figure 11: Process of characterization and abstraction of the Nephelium lappaceum seed. Reliefs category (Photography by Valentina Cardona and digital modeling by Laura Vargas).
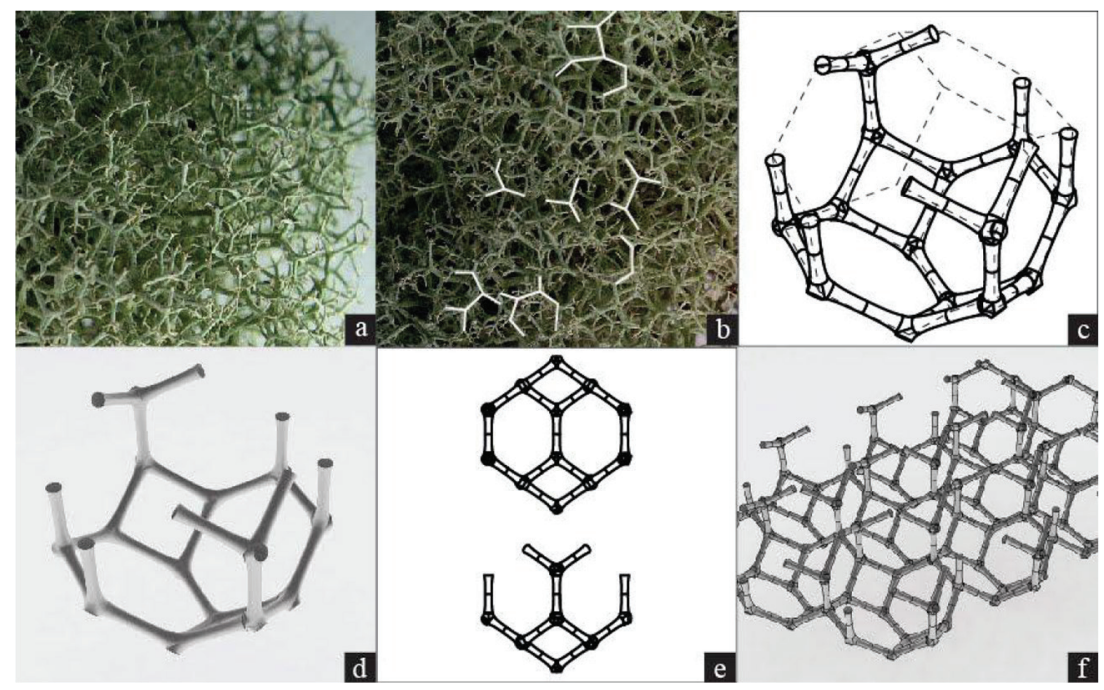

Figure 12: Process of characterization and abstraction of the Icmadophila adversa. Branches category (Photography by Silvia Gallego and digital modeling by Ever Patiño). 


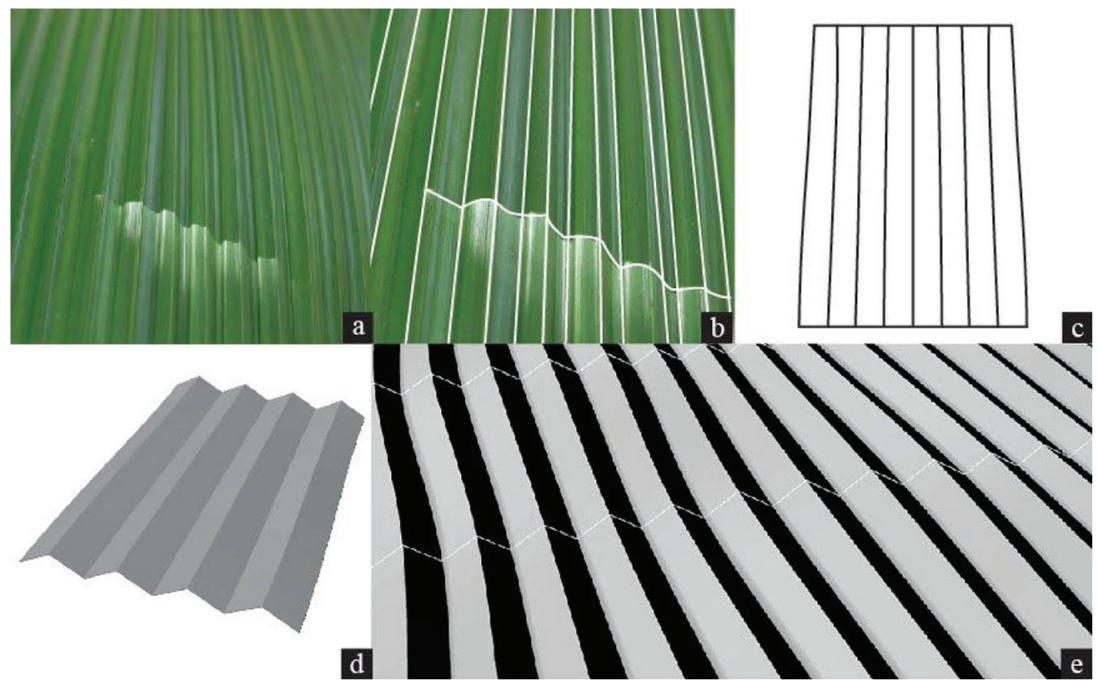

Figure 13: Process of characterization and abstraction of the Washingtonia robusta. Folds category (Photography and digital modeling by Laura Vargas).

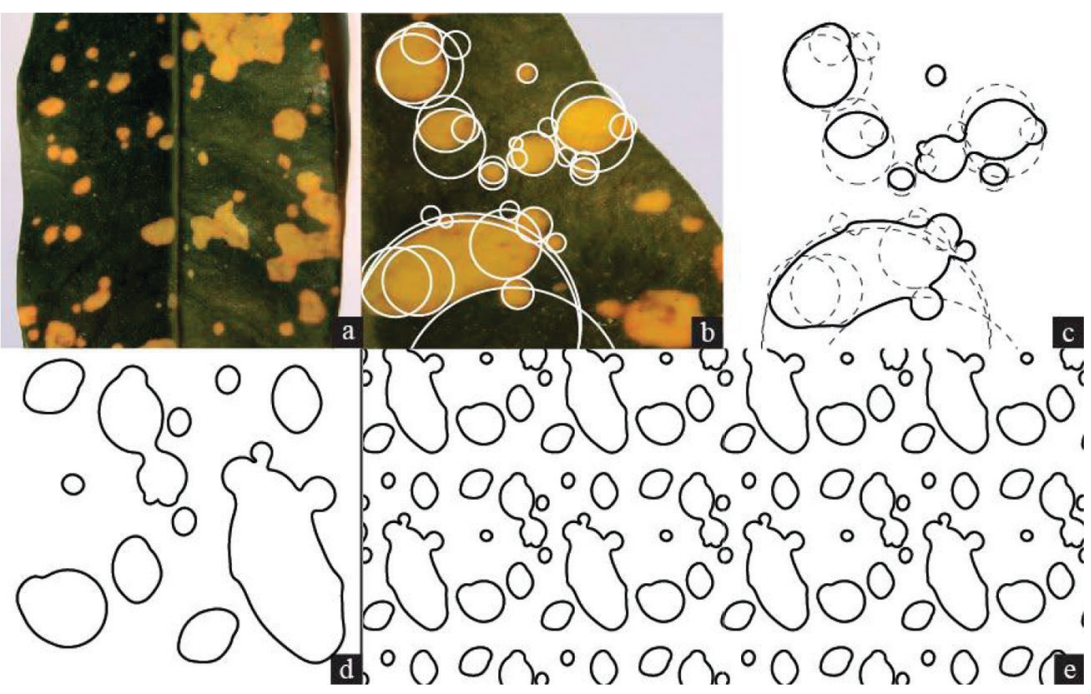

Figure 14: Process of characterization and abstraction of the Blighia sapida leave. Visual texture category (Photography and digital modeling by Laura Vargas). 


\section{CONCLUSION}

The scope of this article is focused on describing the process of classification, characterization and abstraction of biological surfaces and textures so that the designer has guidelines to apply it in their design and/or bio-inspired research projects. According to the project, the designer should ( $i$ ) make an observation in the natural kingdom that best suits his needs, either through observation in the field, or through a documentary search, (ii) classify the information, proposing categories according to the project, (iii) determine morphological and/or functional characteristics that allow us to establish the criteria to (iv) select the species or species that adapt best to the defined problem and $(v)$ perform the geometric or functional abstraction.

The project allows for delimiting the different degrees of hierarchy that can be found in the nature observation, first, from a taxonomic classification that is proper to living beings, and second from the ordering of the different scales of the organism.

The classification of morphological patterns based on their geometric characteristics such as: transition points, contours, symmetries, cross sections and basic patterns such as straight lines, circle sections, circles, ellipses and/or parabolas; it constitutes a useful tool for the realization of abstraction exercises in disciplines such as architecture and design, because it facilitates and orders the process.

The characterization of the digital surfaces and any biological form to be applied to the design must be carried out systematically to obtain results of great depth. At the beginning, with an exploratory approach based on observation and selection and subsequently, with a descriptive approach based on classification, evaluation and abstraction.

In the phase of geometric abstraction, it was necessary to define the level of abstraction required, since the diversity of ways of abstracting could blur the objective of the project. For this reason, an abstraction was defined that conserved the geometric properties of the object of study without reaching an exact copy of the individual.

With the follow-up of the exploratory and descriptive methodology it was possible to verify that three-dimensional interpretation that was made digitally of the textures, conserve the fundamental morphological properties without becoming an exact copy of nature. This was achieved, keeping only those properties with potential to be applied in future design projects.

Finally, for future work, the performing of functional, structural, usability, esthetic and/or sensory evaluations of the textures with the aim to determine specific problematic contexts is proposed and those textures can be used in the design project.

\section{REFERENCES}

[1] Iouguina, A., Dawson, J.W., Hallgrimsson, B. \& Smart, G., Biologically informed disciplines: a comparative analysis of bionics, biomimetics, biomimicry, and bio-inspiration among others. International Journal of Design \& Nature and Ecodynamics, 9(3), pp. 197-205, 2014.

[2] Vincent, J.F., Bogatyreva, O.A., Bogatyrev, N.R., Bowyer, A., \& Pahl, A.K., iomimetics: its practice and theory. Journal of Royal Society Interfase, 3(9), pp. 471-482, 2006.

[3] Jirapong, K., Krawczyk, R.J. \& ElnimeirI, M., Natural Forms as Virtual Architectures. Proceedings of the 20th Conference on Education in Computer Aided Architectural Design in Europe, pp. 1-4, 2002.

[4] Wen, H.I., Zhang, S.J., Hapeshi, K. \& Wang, X.F., An innovative methodology of product design from nature. Journal of bionic engineering, 5(1), pp. 75-84, 2008.

[5] Tsipenyuk, A. \& Varenberg, M., Use of biomimetic hexagonal surface texture in friction against lubricated skin. Journal of The Royal Society Interface, 11(94), 2014. 
[6] Bormashenko, E., Wetting transitions on biomimetic surfaces. Philosophical Transactions of the Royal Society of London A: Mathematical, Physical and Engineering Sciences, 368(1929), pp. 4695-4711, 2010.

[7] Otten, A. \& Herminghaus, S., How plants keep dry: a physicist's point of view. Langmuir, 20(6), pp. 2405-2408, 2004.

[8] Zhang, X., Shi, F., Niu, J., Jiang, Y. \& Wang, Z., Superhydrophobic surfaces: from structural control to functional application. Journal of Materials Chemistry, 18(6), pp. 621-633, 2008.

[9] Feng, L., Zhang, Y., Xi, J., Zhu, Y., Wang, N., Xia, F. \& Jiang, L., Petal effect: a superhydrophobic state with high adhesive force. Langmuir, 24(8), pp. 4114-4119, 2008.

[10] Tuteja, A., Choi, W., McKinley, G.H., Cohen, R.E. \& Rubner, M.F., Design parameters for superhydrophobicity and superoleophobicity. MRS bulletin, 33(8), pp. 752-758, 2008.

[11] Dai, Z., Tong, J. \& Ren, L., Researches and developments of biomimetics in tribology. Chinese Science Bulletin, 51(22), pp. 2681-2689, 2006.

[12] Lee, S.M., Lee, H.S., Kim, D.S. \& Kwon, T.H., Fabrication of hydrophobic films replicated from plant leaves in nature. Surface and Coatings Technology, 201(3), pp. 553-559, 2006.

[13] Helms, M., Vattam, S.S. \& Goel, A.K., Biologically inspired design: process and products. Design Studies, 30(5), pp. 606-622, 2009.

[14] Moreno, D., Blessing, L., Yang, M. \& Wood, K., The potential of design-by-analogy methods to support product, service and product service systems idea generation. $D S$ 80-5 Proceedings of the 20th International Conference on Engineering Design (ICED 15) Design Methods and Tools-Part 1,5, pp. 27-30, 2015.

[15] Volstad, N.L. \& Boks, C., On the use of Biomimicry as a Useful Tool for the Industrial Designer. Sustainable Development, 20(3), pp. 189-199, 2012.

[16] Appio, F.P., Achiche, S., Martini, A. \& Beaudry, C., On designers' use of biomimicry tools during the new product development process: an empirical investigation. Technology Analysis \& Strategic Management, 29(7), pp. 775-789, 2017.

[17] Wagensberg, J., La rebelión de las formas, Editorial Matemas: Barcelona, 2004.

[18] Gorb, S., Functional Surfaces in Biology: Mechanisms and Applications. En: Biomimetics. Biologically Inspired Technologies, ed. Y. Cohen, Taylor and Francis Group: Boca Raton, pp. 381-397, 2006.

[19] Fu, K.D., Moreno, D. Yang, M. \& Wood, K.L., Bio-inspired design: an overview investigating open questions from the broader field of design-by-analogy. Journal of Mechanical Design, 136(11), pp. 1-18, 2014.

[20] Stevens, P., Patrones y pautas en la naturaleza. Salvat Editores: Barcelona,1987.

[21] Otto, F., Form IL22, Institute for Lightweight Structures. University of Stuttgart: Federal Republic of Germany, 1988.

[22] Aranda, B. \& Lasch, C., Tooling, Pamphlet Architecture 27. Princeton Architectural Press: New York, 2006.

[23] Arbeláez, E. \& Patiño, E., Generación y transformación de la forma. Editorial Universidad Pontificia Bolivariana: Medellín, 2009.

[24] Valencia-Escobar, A.H. Forma, estructura y movimiento: Variables de diseño morfológico para objetos industriales estructurales y dinámicos, Universidad Pontificia Bolivariana:Medellín, 2006.

[25] Escobar, A.V., Elementos de la forma, la estructura y el movimiento. Iconofacto, 3(4), pp. 60-85, 2007. 
[26] Thompson, D., Sobre el crecimiento y la forma, Cambridge University Press: Madrid, 2000.

[27] Steward, I. \& Golubitsky, M., ¿Es Dios un geómetra?: las simetrías de la naturaleza, Crítica., Barcelona, Drakontos Series, 1995.

[28] Villate, M.C. 2008. Estructuras no convencionales en arquitectura, Univerdidad Nacional de Colombia:Bogotá, 2008.

[29] Pugnale, A. \& Sassone, M., Structural reciprocity: critical overview and promising research/design issues. Nexus Network Journal, 16(1), pp. 9-35, 2014.

[30] Portugali, J., SIRN - Synergetic Inter-Representation Networks BT - Complexity, Cognition and the City, In ed. J. Portugali, Springer Berlin Heidelberg:Berlin, pp. 139-165, 2011.

[31] Schopfer, P., Biomechanics of plant growth. American Journal of Botany, 93(10), pp. 1415-1425, 2006.

[32] Bharat, B., Biomimetics: lessons from nature-an overview. Philosophical Transactions: Mathematical, Physical and Engineering Sciences, 367(1893), pp. 1445-1486, 2009.

[33] Fleury, V., Gouyet, J.F. \& Léonetti, M. (eds), Branching in Nature: Dynamics and Morphogenesis of Branching Structures, from Cell to River Networks, Springer Science \& Business Media:Berlin, 2013.

[34] Hallé, F., Branching in Plants BT - Branching in Nature, In eds. V. Fleury, J.F. Gouyet, M. Léonetti, Springer Berlin Heidelberg, Berlin, Heidelberg, pp. 23-40, 2001.

[35] Sierra, D., Sañudo, F. \& Vanegas, G., Estructuras ligeras, Universidad Pontificia Bolivariana:Medellín, 2006.

[36] Koch, K., Bhushan, B. \& Barthlott, W., Multifunctional surface structures of plants: an inspiration for biomimetics. Progress in Materials science, 54(2), pp. 137-178, 2009.

[37] Allen, I.E. \& Seaman, C.A., Likert scales and data analyses. Quality progress, 40(7), pp. 64-65, 2007.

[38] Baumeister, D., Tocke, R., Dwyer, J., Ritter, S. \& Benyus, J.M., Biomimicry Resource Handbook: A Seed Bank of Best Practices. Biomimicry 3.8: E.E.U.U, 2014.

[39] Comanns, P., Winands, K., Arntz, K., Klocke, F. \& Baumgartner, W., Laser-Based Biomimetic Functionalization of Surfaces: From Moisture Harvesting Lizards To Specific Fluid Transport Systems. International Journal of Design \& Nature and Ecodynamics, 9(3), pp. 206-215, 2014.

[40] Verein Deutscher Ingenieure. Handbuch Bionik, VDI 6220. www.vdi.eu/uploads/tx_ vdirili/pdf/1751320.pdf. (accessed 12 June 2011).

[41] Hekkert, P. \& Helmut, L., Product Aesthetics. Product Experience, Elsevier, pp. 259-285, 2008.

[42] Ramachandran, V.S. \& Hirstein, W., The science of art: A neurological theory of aesthetic experience. Journal of Consciousness Studies, 6(6-7), pp. 15-51, 1999.

[43] Hekkert, P., Design aesthetics: Principles of pleasure in design. Psychology Science 48(2), pp. 157-172, 2006. 